\title{
Producción, circulación y divulgación de conocimiento histórico en el Museo Mitre de la ciudad de Buenos Aires (1906-1946)
}

\author{
Production, circulation and dissemination of historical knowledge in \\ the Mitre Museum of the city of Buenos Aires (1906-1946)
}

\author{
Maria Elida Blasco \\ eliblasco@yahoo.com.ar \\ Professora \\ Consejo Nacional de Investigaciones Científicas y Técnicas (CONICET) \\ 25 de Mayo $221,2^{\circ}$ piso \\ 1002 - Buenos Aires \\ Argentina
}

\section{Resumen}

El artículo analiza el contexto en el que se produjeron los primeros canales de contacto entre historiadores y espacios museográficos. El objetivo general se orienta a vincular la historia de la historiografía con el establecimiento de espacios culturales no orientados de manera exclusiva a la investigación y la enseñanza formal de la disciplina. El objetivo específico es reconstruir los primeros cuarenta años de funcionamiento del Museo Mitre creado en 1906 para conservar la biblioteca, el archivo, los objetos de uso personal y la composición de los ambientes del edificio en donde había vivido Bartolomé Mitre (1821-1906), consagrado en la Argentina como un prócer nacional por su actuación política, militar e historiográfica. Consideramos que dada la centralidad de la figura de Mitre y la influencia que generó su producción historiográfica, el Museo adquirió gran protagonismo en la vida cultural de la primera mitad del siglo XX vinculando la práctica de la historia con su representación y divulgación mediante la puesta museográfica.

\section{Palabras claves}

Historiografía; Historiadores; Museos.

\begin{abstract}
The article analyses the context in which took place the first channels of contact between historians and museographic spaces. The general goal aims at linking the history of historiography with the establishment of cultural spaces not oriented in an exclusive manner to the investigation and the formal teaching of the discipline. The specific goal is to reconstruct the first forty years of operation of Mitre Museum, created in 1906 to maintain the library, the archive, the objects of personal use and the composition of the rooms at the building where Bartolome Mitre (1821-1906) lived, consecrated in Argentina as a national leader for his political, military and historiography performance. We consider that because of the centrality of Mitre figure and the influence that generated his historiographical production, the Museum acquired a major role in the cultural life of the first half of twentieth century linking the history practice with its representation and dissemination by means of the museographic set.
\end{abstract}

Keywords

Historiography; Historians; Museums.

Recibido el: 26/8/2015

Aceptado el: 8/3/2016 
En la actualidad argentina el conocimiento histórico se propaga por espacios sociales tan amplios como ajenos a los agentes que lo producen, dado que en la mayoría de los casos estos se recluyen en ámbitos académicos más interesados en fortalecer el rigor científico que en la divulgación. Los museos vinculados a lo histórico constituyen ejemplos paradigmáticos de este fenómeno dado que - a excepción de casos puntuales promovidos durante la última década - sus exhibiciones son producidas por agentes vinculados al ámbito de la museología que se nutren de conocimientos generales de la historia pero no están insertos en las prácticas académicas de la disciplina histórica. ${ }^{1}$ Las cientos de miles de personas que visitan anualmente los museos históricos de la Argentina reciben conocimientos interpretados, seleccionados y redefinidos previamente por un amplio espectro de operadores generalmente desvinculados de la producción historiográfica. ${ }^{2}$ Sin embargo, esta disociación no fue siempre así. En 1938 los historiadores de mayor prestigio académico constituyeron la Comisión Nacional de Museos y Monumentos y Lugares Históricos (CNMyMyLH), surgida para delinear políticas públicas de intervención sobre bienes de interés histórico y administrar los museos históricos dependientes del Ministerio de Justicia e Instrucción Pública de la Nación. Esta Comisión dirigida por Ricardo Levene, en 1939 tuvo a su cargo la instalación del Museo Histórico del Cabildo y la Revolución de Mayo.

Este artículo propone remontarse al origen del acercamiento entre investigadores de la historia y espacios museográficos centrando la atención en 32 el Museo Mitre de la ciudad de Buenos Aires, creado como institución pública en 1906. Este museo funcionó - y aún funciona- en la casaen donde vivió Bartolomé Mitre (1821-1906) desde que dejó su cargo de Presidente de la Nación en 1868, hasta su muerte. ${ }^{3}$ Fue el segundo museo de carácter histórico organizado en el país - el primero fue el Museo Histórico Nacional (MHN) creado en 1889 (CARMAN 2013) - y se constituyó con el propósito de conservar la biblioteca, el archivo, los objetos de uso personal y hasta la composición de los ambientes para evocar la vida y obra de una figura consagrada como "prócer nacional" aún antes de su muerte debido a su actuación política, militar e historiográfica (BLASCO 2015a). Recordemos que al momento de su fallecimiento, Mitre presidía la Junta de Historia y Numismática Americana (JHNA) que desde 1893 nucleaba a coleccionistas e historiadores (RAVINA 1995).

\footnotetext{
${ }^{1}$ Recordemos por ejemplo que a diferencia de Brasil, en la Argentina las carreras de formación de museólogos orientados a las humanidades están desvinculadas de los organismos de formación científica - a excepción de algunos centros vinculados a las universidades- y que recién en los últimos años algunos historiadores mostraron interés en los procesos de formación de colecciones y museos de carácter histórico.

2 Entre el año 2005 y 2011 el Museo Nacional del Cabildo y de la Revolución de Mayo situado en la ciudad de Buenos Aires fue visitado por 1.224 .890 personas. Se trata de un museo representativo de los acontecimientos sucedidos el 25 de mayo de 1810, que los argentinos consideran fundacionales de la nación y que en el marco de los festejos del bicentenario fueron sometidos a revisión y debate público del que se hicieron eco los historiadores profesionales dando cuenta de la amplitud de temas y perspectivas vinculadas al proceso revolucionario que la historiografía ha producido en las últimas décadas. Sin embargo, las exhibiciones del Museo permanecieron ajenas a estos replanteos. Sobre el número de visitantes, cf.: DIRECCIÓN GENERAL DE ESTADISTICA Y CENSO 2011, p. 265.

${ }^{3}$ Era un inmueble alquilado por Mitre en 1860 que en 1868 le fue obsequiada por una comisión de personas que reunió el dinero para adquirirla. Está situada en la calle San Martín 336 de la ciudad de Buenos Aires. Sitio web del Museo Mitre: http://www.museomitre.gob.ar/.
} 
Nos proponemos reconstruir los primeros cuarenta años de funcionamiento del Museo para explorar el desarrollo de prácticas culturales vinculadas tanto a la investigación histórica como a la representación y divulgación del conocimiento mediante la puesta museográfica. Dada la centralidad que adquirió la figura de Mitre y la influencia que generó su producción historiográfica, el Museo consiguió gran protagonismo en la vida cultural de la primera mitad del siglo XX y convocó al mismo tiempo tanto a los investigadores de la historia como al público no especializado: por sus patios y salones circulaban historiadores profesionales, aficionados, periodistas, empleados, docentes, estudiantes, políticos y público en general que no solo compartía espacios físicos sino que, muchas veces, intervenían de manera conjunta en la conformación de asociaciones e instituciones de la vida cultural porteña que adoptaban el Museo como sede.

El período bajo análisis se inicia en el año 1906, cuando el Estado adquirió el inmueble y los herederos de Mitre donaron la biblioteca, la mapoteca, el monetario, el mobiliario y todos los objetos existentes al momento del fallecimiento para conformar el Museo. Culmina en 1946, cuando se realizó la donación del archivo privado de Mitre que se hallaba a disposición en el Museo pero hasta el momento continuaba en propiedad de la familia.

\section{Un museo al servicio de los historiadores (1906-1938)}

La idea de instalar un museo en la casa de Mitre comenzó a concebirse durante los meses previos a la muerte del prócer, cuando el propietario del inmueble manifestó a su familia la intención de donar sus bienes al Estado. El 19 de enero de 1906, durante los funerales, el ingeniero Emilio Mitre - hijo de Bartolomé, líder del Partido Republicano y director del influyente diario $L a$ Nación (ZIMMERMANN 1998) - divulgó la noticia de que la biblioteca privada podría transformarse en institución pública. Meses después se presentó un Proyecto de Ley propiciando la compra por parte del Estado de la casa en la que había vivido Mitre para conformar un museo con la biblioteca, las colecciones, el archivo y los muebles que serían donados por los herederos. Se trataría del primer museo con sede en una casa particular considerada histórica que se traducía en una primera instancia conmemorativa de explícito contenido político (BISSO; KAHAN 2014): no casualmente el 26 de junio de 1906 - el día que se cumplía el 85 aniversario del nacimiento de Mitre - el proyecto se transformó en ley (BLASCO 2015a).

El 7 de julio el Poder Ejecutivo encargó al Poder Judicial que fijarael precio de adquisición de la casa. ${ }^{4}$ En representación de los herederos, Emilio Mitre manifestó que respetando la voluntad de su padre ponía a disposición del gobierno la biblioteca y el monetario americano para que se conserven en la casa como parte del museo que se instalaría. Aunque nada expresaba respecto al archivo privado que al parecer continuaría siendo propiedad de la familia, mencionaba que el catálogo de los libros y el monetario estaba siendo confeccionado por 
el numismático Alejandro Rosa, vicepresidente de la JHNAal momento del fallecimiento de Mitre, que valoraba los materiales como insumos indispensables para el trabajo de investigación historiográfica. Además - informaba Emilio - completarían la donación "con la de todos los muebles, cuadros, bronces y objetos de uso" que tenía su padre hasta el día de su muerte "y que hoy se encuentran en sus habitaciones en la misma disposición que él les dio": al parecer, conservar la distribución del "interior doméstico" era de importancia para una familia cuya función, consideraba, era perpetuar la memoria para que las futuras generaciones evocaran al prócer" en su propio ambiente". La idea de preservar el "interior doméstico" no dejaba de ser innovadora dado que desplazaba la atención generada por los objetos vinculados de manera exclusiva a los acontecimientos políticos y militares del pasado de la Argentina - banderas, uniformes militares, armas, etc. por entonces preservados en el MHN - hacia las piezas de uso cotidiano del "gran hombre" evocado como civil.

El 24 de agosto se determinó que el Estado debería pagar un millón de pesos para adquirir la casa. Días después el Poder Ejecutivo firmó el decreto aceptando la suma indicada y la donación realizada por los herederos. También establecía que el Estado se haría cargo de los gastos de conservación de la casa mientras se efectuara la transmisión definitiva, pero no fue aceptado por la familia que consideró que debía continuar a su cargo. El 29 de noviembre se expidió la orden de pago a favor de los herederos de Mitre. Luego el Escribano de Gobierno confeccionó la escritura y el 15 de diciembre de 1906 los descendientes se reunieron en el despacho del 34 Presidente de la Nación, José Figueroa Alcorta, para rubricar sus firmas y finalizar el trámite. El traspaso de la vivienda particular a propiedad estatal había sido extremadamente veloz: se había iniciado doce días después de sancionada la ley y culminaba exitosamente luego de cinco meses mostrando un sólido consenso.

El Museo fue inaugurado el 3 de junio de 1907 bajo la dirección de Alejandro Rosa que si bien vinculaba a la institución con las prácticas de la historia como disciplina científica, tal como había sido consagrada por el fallecido Mitre, intentaba dotarla de una impronta más popular. El 26 de junio, por ejemplo, organizó el cumpleaños del prócer repitiendo los rituales de años anteriores, cuando Mitre recibía a sus amigos y se asomaba al balcón para saludar a sus seguidores que se agolpaban en las calles. Ante la ausencia física del "gran hombre", Rosa mandó a acuñar medallas con el rostro del homenajeado y quienes se asomaron al balcón fueron los alumnos y maestros de las escuelas cercanas para ser retratados por la prensa. ${ }^{5}$ Era evidente que la casa comenzaba a transformarse en lugar evocativo que recordaba a un hombre devenido prócer.

En septiembre de 1907 el Ministerio de Justicia e Instrucción Pública envió al director del Museo Mitre el reglamento que desde 1899 regía para el Archivo General de la Nación (AGN), por entonces a cargo de José Juan Biedma, amigo de Mitre y de Rosa y miembro de la JHNA desde $1901 .{ }^{6}$ La idea era que se

\footnotetext{
${ }^{5}$ Aniversario del natalicio del general Mitre. Caras y Caretas, n. 457, 6 de julio de 1907, p. 2.

${ }^{6}$ Carta de Juan Bautista Gómez al Director del Museo, 14/9/1907; AE C16 C2 n. 27, Archivo Museo Mitre. Se adjunta Reglamento del Archivo General de la Nación [Buenos Aires, Taller Tipográfico de la Penitenciaría Nacional, 1899] redactado por el director Agustín Pardo entre 1894 y 1904.
} 
adoptara el mismo texto lo cual no era inverosímil si se considera que la práctica de reglamentar el funcionamiento interno de instituciones públicas era aún incipiente ${ }^{7}$ y que el mayor interés de los estudiosos de la JHNA estaba puesto en la biblioteca - ahora pública - del Museo Mitre y el archivo, propiedad de la familia. También reflejaba la distancia establecida con otros museos cuyos propósitos principales eran la conservación de objetos diferentes a los libros y papeles que el Museo ponía al servicio de la historia como disciplina científica y no como material ilustrativo. En realidad los demás elementos entregados por la familia eran poco atractivos para los investigadores comparados con la riqueza de los documentos; sin embargo Rosa incrementó las colecciones solicitando piezas a sus conocidos y aceptando donaciones de particulares. ${ }^{8}$

Si bien la atención de los investigadores estaba puesta en descubrir los secretos de la biblioteca, Emilio Mitre logró que el atractivo fuera también el diario La Nación que dirigía. El 18 de marzo de 1908 el periódico comenzó a publicar algunos documentos del archivo privado que poseía la familia. La nota de presentación evocaba la honradez intelectual y política de Bartolomé recordando que no había querido hacer un uso público de los documentos que había acumulado a lo largo de su vida porque creía que "el debate histórico no debía abrirse sino cuando, desaparecidos los actores y calladas las pasiones, pudiera encontrar un ambiente de serena imparcialidad para el juicio de los hombres" y solo había quebrantado ese propósito cuando acusaron a la Argentina de haber prolongado la Guerra del Paraguay (MITRE 1911, p. X). La crónica eludía mencionar que en realidad se trataba de un hombre que había poseído en su archivo los documentos vinculados a su actuación como Gobernador de Buenos Aires y Presidente de la Argentina que deberían haber permanecido en una repartición pública. Luego aclaraba que ahora, muerto Mitre, había llegado la hora de comenzar a publicarlos para luego entregarlos al Museo; pero tampoco reflexionaba sobre el hecho de que era el hijo del fallecido quien seleccionaba el material que se divulgaba en el diario propiedad de la familia. Para finalizar, exponía:

Las piezas del archivo del General Mitre no son guijarros destinados a golpear ningún tejado: son piedras para el edificio de la historia contemporánea de la República Argentina, reunidas por el primero de sus obreros [...] su obra no puede renovar divisiones de largo tiempo allanadas, sino, por el contrario, confirmar la paz adquirida y apaciguar del todo las pasiones que todavía no hayan terminado de aquietarse (MITRE 1911, p. XII).

Sucedía que Emilio decidía dar a conocer los documentos en un contexto en donde el ideario político de Mitre continuaba ejerciendo influencia sobre la opinión pública. Ello contribuyó pero también condicionó los modos de organización del Museo.

\footnotetext{
7 EI MHN redactó su reglamento en 1923. Agradezco el dato a Carolina Carman.

${ }^{8}$ Angiolina Astengo de Mitre, esposa del recién fallecido Emilio Mitre, donó un reloj y una cadena usada por Bartolomé perteneciente a su fallecido hijo Adolfo; carta al director Alejandro Rosa, 5/6/1909; Armario 8, número 12414; Archivo Museo Mitre.
} 
A fines de 1908 se propuso celebrar el centenario de la Revolución de Mayo con un congreso de historia americana en el Museo Mitre. Además se pensó en trasladar allí, de manera temporaria, la JHNA que desde 1906 funcionaba en el antiguo edificio del Congreso Nacional. Aunque en los años siguientes los investigadores continuaron reuniéndose puertas afuera del Museo su director orientó la labor institucional a la edición y recopilación documental a semejanza de lo que realizaba el AGN. Con apoyo económico del Ministerio de Justicia e Instrucción Pública y de la Comisión Nacional del Centenario editó catálogos y compilaciones de documentos del archivo particular de Mitre vinculados a San Martín, Belgrano, la época colonial y el período de la independencia, aunque los concernientes a la actuación pública del prócer continuaban siendo seleccionados por la familia. Al menos hasta 1915 no se publicaron guías, catálogos o álbumes del interior del Museo (MUSEO MITRE 1914) ya que la disposición del mobiliario no era el principal interés del director.

En marzo de 1910, en el marco de los preparativos de los festejos por el centenario de la Revolución de Mayo, el diario La Nación - codirigido ahora por Luis Mitre y su primo menor Jorge Adolfo Mitre ${ }^{9}$ - volvió sobre el archivo y publicó un volumen con la correspondencia. En la advertencia Jorge alertaba sobre las modificaciones realizadas por los editores:

Cartas confidenciales [...] escritas algunas bajo la impresión de las contiendas civiles o militares y sin el propósito de que vieran la luz pública en esos momentos; tal cual apreciación de carácter exclusivamente personal, consignadas al pasar, desprovistas en absoluto de importancia para aclarar los sucesos o definir actuaciones decisivas, han puesto a los editores en el caso de suprimirlas unas veces o de substituir en otras el nombre del aludido por una inicial arbitraria y obviar así, sin mengua de la importancia histórica de ningún documento, el inconveniente señalado, propio del carácter que puede llegar a revestir una comunicación confidencial (MITRE 1911, p. VIII).

Sin embargo, mencionaba que si algunas apreciaciones incidentales en esas cartas fueran de interés al lector, podría dirigirse al Museo Mitre para confrontarlas con los documentos originales.

Durante la gestión de Alejandro Rosa el Museo había funcionado como custodio de los libros y documentos considerados fundamentales para la escritura de la historia y la interpretación del pasado todavía reciente. A su muerte, en 1914, la dirección pasó a manos de Luis Mitre: Luis no provenía del ámbito de la investigación ni ejercía la docencia universitaria, sin embargo fue invitado a incorporarse a la JHNA (RAVINA 1995, p. 76; 92) como homenaje a su abuelo y con el objeto de fortalecer los vínculos con el Museo y el diario. Por ese entonces también comenzó la carrera de ascenso a la escena pública de Ricardo Levene - que en 1914 se integró a la JHNA- y de Rómulo Zabala (AAVV 1950) estudioso de la historia, periodista, editorialista y jefe de archivo de La Nación y conocedor de los secretos de la casa dado que su madre había sido el

${ }_{9}^{9}$ El cambio de dirección respondió al fallecimiento de Emilio Mitre en 1909. Luis y Jorge Adolfo eran nietos de Bartolomé Mitre. 
ama de llaves hasta el fallecimiento de Mitre. Incorporado Levene y Luis Mitre a la JHNA y con Zabala a cargo del archivo se afianzó la idea de que el Museo debía ser el ámbito de socialización de los investigadores. Desde 1918 uno de sus salones se trasformó en la sede de la JHNA y en el escenario en donde la nueva generación de historiadores realizaba reuniones privadas y conferencias públicas mientras intercambiaba datos sobre investigaciones en curso (RAVINA 1995, p. 70 ; 73). ${ }^{10}$ Además, allí se reunían las comisiones del Patronato Nacional de Sitios y Monumentos Históricos instituido en 1919 para relevar lugares de interés histórico (BLASCO 2012).

La importancia de la biblioteca y el archivo de Mitre generó que las personas a cargo de su ordenamiento y catalogación se ganaran la confianza de los historiadores como proveedores de datos, libros y documentos mientras incorporaban las prácticas relacionadas con la investigación: Zabala, por ejemplo, se incorporó a la JHNA en 1922, en 1923 fue prosecretariotesorero y en 1924 director del boletín de la entidad. También sucedía que los historiadores de la JHNA veían en el Museo un espacio apto para desarrollar sus investigaciones contando con un sueldo provisto por el Estado: fue el caso de Juan Ángel Farini, miembro de la JHNA desde 1915, quien ingresó a trabajar en el Museo como escribiente en abril de 1924. ${ }^{11}$ Claramente el Museo comenzaba a transformarse en un dispositivo clave que acompañaba el proceso de distinción entre saber especializado y amateur y promovía el desarrollo de las prácticas específicas de la historiografía como disciplina científica propias de las décadas de 1910 y 1920 (EUJANIAN 2003).

Aunque durante este período la puesta museográfica del Museo Mitre no era un gran atractivo para el público que lo frecuentaba, ${ }^{12}$ conviene considerar que fue la primera institución que exhibió reconstrucciones de ambientes tal como estaban dispuestos en vida del propietario de la casa: ello constituyó una experiencia innovadora capitalizada por algunos promotores culturales ávidos por implementar estrategias para divulgar la historia a través de la escenificación y la representación museográfica. Primero fue el publicista e historiador Enrique Udaondo - visitante asiduo del Museo- que se inspiró en ellas para diseñar las exposiciones "didácticas y modernas" del Museo Histórico y Colonial de la Provincia de Buenos Aires que iba a dirigir desde 1923 (BLASCO 2011). El Museo tenía sede en el edificio donde había funcionado el Cabildo de la Villa de Luján y asumía características notables que lo diferenciaban del MHN. Este último se abocaba a la exhibición de "las reliquias capitales" de la vida política y militar de la Argentina donde predominaba un criterio de exposición convencional de los objetos; en Luján en cambio se había organizado un museo "colonial" que evocaba la vida "urbana" de la Villa en la época de la colonia y se caracterizaba por un despliegue expositivo que interpelaba más a la emotividad y a los sentidos del público: maniquíes de cera con atuendo de época

\footnotetext{
10 Desde 1919 Levene ocupó el cargo de secretario.

${ }^{11}$ Fichas de calificación del personal enviadas por el Subdirector del Museo Jorge A. Mitre al Director Interino de la CNMyMH Aníbal F. Imbert, 11/12/1947; Legajo 316. Personal- varios- calificaciones. Museo Mitre. Carpeta 2, Archivo de la CNMyMyLH. Datos biográficos de Farini en Quien es Quien (1955, p. 241).

${ }^{12}$ Continuaba sin publicarse una guía ilustrada y que recién en 1925 se editará el primer catálogo de la Sección Numismática.
} 
interactuaban con animales embalsamados que otorgaban realismo a los escenarios que reconstruían la vida cotidiana de "antaño".

Además, con el paso del tiempo Udaondo se propuso que el Museo representara "todo el pasado de la nación" y evocara a sus héroes representativos, por lo tanto en 1926 expuso una figura de cera de tamaño natural de Mitreconstruida en base a la maqueta de la estatua ideada por el escultor español Torcuato Tasso: el maniquí lo reproducía en traje de civil, vistiendo la ropa que había usado en vida con el objeto de convertirlo en héroe inmortal. También en 1927 inauguró una sala reconstruyendo el dormitorio de una de las hijas de Mitre fallecida en 1925 con la donación del mobiliario realizadas por sus familiares. Años más tarde el director del MHN adoptó estrategias museográficas similares al instalar la "sala-dormitorio de José de San Martín" en el marco de los homenajes por el aniversario de su muerte: la idea era reconstruir los ambientes con el mobiliario original que constaba en el museo desde 1899 donados por la nieta del prócer y solicitar al gobierno francés las reconstrucciones de las puertas, ventanas, rejas y demás ornamentos del edificio que había habitado el prócer en Boulogne-Sur-Mer (BLASCO 2012). El Museo Mitre fue entonces el primer ámbito que posibilitó y promovió el conocimiento y la observación de prácticas culturales vinculadas a las maneras de evocar el pasado y representarlo museográficamente para un público heterogéneo.

Finalmente, en los diez años comprendidos entre 1927 y 1937 los historiadores auto-filiados herederos de Mitre e identificados como la Nueva Escuela Histórica (DEVOTO; PAGANO 2009, p. 13-14, 139-200) fueron consolidando una relación cada vez más simbiótica con el Museo, acompañados por Farini que ante el alejamiento de Zabala era el "nexo" entre el archivo, la biblioteca y los investigadores. ${ }^{13}$ A su vez durante la década de 1930 se replanteó la cuestión de la divulgación de la historia patriótica (SUAREZ; SAAB 2012) y la presencia del pasado en diferentes ámbitos de la sociedad se hizo más evidente que en las décadas anteriores (CATTARUZZA 2001). Levene comenzó a erigirse en historiador de referencia (QUATTROCCHI-WOISSON 1995, p. 141-162; RODRÍGUEZ 2001) y dirigía la edición de La Historia de la Nación Argentina por indicación del gobierno nacional ejercido por su amigo Agustín P. Justo.Mientras tanto se profundizaba el apoyo oficial a la labor de la JHNA y el Museo Mitre se trasformaba en un espacio frecuentado por intelectuales de renombre del ámbito nacional e internacional ${ }^{14}$ que lentamente supieron sacar provecho de las experiencias acumuladas en materia de organización de museos, señalamiento de lugares históricos, conservación de restos materiales y prácticas conmemorativas. Efectivamente hacia mediados de la década de 1930 la protección de monumentos y la promoción de museos

\footnotetext{
${ }_{13}$ Recordemos que Levene fue presidente de la JHNA entre 1927 y 1931 y entre 1934 y 1938 , GIRBAL DE BLACHA 1995. En 1931 Zabala fue nombrado director del Museo Municipal de Arte Colonial. Entre 1931 y 1935 Farini fue auxiliar de biblioteca y entre 1935 y 1944 contador habilitado del Museo.

${ }_{14}$ Ver por ejemplo secciones Conferencias y Actos públicos realizados por la Junta en tomos XVIII al XI de los boletines de la JHNA. También en esos años surgió la Institución Mitre con sede en el Museo; Información nacional. Dr. Ángel Gallardo. El Monitor de la Educación Común, n. 737, mayo de 1934, p. 80. En 1937 el Museo fue sede de la Comisión Nacional de Publicación de las Obras Completas de Bartolomé Mitre presidida por el Presidente Justo; Nota de Juan A. Farini a Julio César Gancedo, 16/7/1968, Museo Mitre, carpeta 1, Archivo de la CNMyMyLH. En los salones del Museo también se realizaron jornadas del II Congreso Internacional de Historia de América en julio de 1937.
} 
eran temas instalados en la agenda pública promovidos por estudiosos del arte y de la historia, representantes diplomáticos y funcionarios públicos con algún grado de interés en la investigación y divulgación histórica (BLASCO 2012). En este marco, en 1937 - luego de treinta años de inaugurado- se editó el primer catálogo ilustrado de las colecciones y la reconstrucción de los ambientes de la casa en donde había vivido Mitre (MUSEO MITRE 1937).

\section{Historiadores y museos al servicio del público (1938 y 1946)}

Desde abril de 1938 el Museo Mitre pasó a depender de la recién creada CNMyMyLH presidida por Levene y puesta bajo jurisdicción del Ministerio de Justicia e Instrucción Pública. ${ }^{15}$ La nueva institución estaba integrada "por personas destacadas en el conocimiento y estudio de la historia patria" como José Torre Revello, Emilio Ravignani, Ramón J. Cárcano, Luis Mitre, Enrique Udaondo y Rómulo Zabala. No casualmente los elegidos eran miembros de la JHNA - recientemente transformada en Academia Nacional de la Historia (ANH)y ninguno acogía con simpatía la cada vez más notoria actuación pública de los historiadores revisionistas que desde el flamante Instituto Juan Manuel de Rosas ponían en tela de juicio los beneficios de la herencia liberal dejada por Mitre (CATTARUZZA 2003).Según el decreto gubernamental Luis Mitre asumiría la vicepresidencia de la CNMyMyLH sin considerar que ello pudiera ser incompatible con su cargo de director de museo, dado que la Comisión debería controlar también el funcionamiento del Museo Mitre.

A fines de mayo de 1938 el Museo comenzó a oficiar de sede provisoria de la CNMyMyLH reuniendo a sus miembros en la misma sala donde funcionaba la AHN. Luis Mitre renunció a la vicepresidencia de la Comisión, según argumentó, por falta de tiempo; continuó como vocal ante la insistencia de Levene, pero en la práctica quien representaba los intereses del Museo era Rómulo Zabala, quien secundaba a Levene en la vicepresidencia de la AHN. ${ }^{16}$

Desde que pasó a estar supeditado a la CNMyMyLH se intentó que el Estado incrementara los recursos económicos asignados al Museo. Concretamente se aprobó un nuevo presupuesto institucional para el año 1939 que incrementaba notablemente el vigente y que colocaba al Museo en segundo lugar en cuanto a nivel de gastos luego del MHN (Actas, sesión del 14 y 22/6/1938, COMISIÓN NACIONAL DE MUSEOS Y DE MONUMENTOS Y LUGARES HISTÓRICOS 1939, p. 194, 197-201). También era el segundo en cuanto a cantidad de empleados: mientras el MHN contaría con veinticinco incluyendo al director y vicedirector, el Museo Mitre tendría diecisiete, solo que su director ejercería el cargo ad honorem. Finalmente respecto a las prioridades de gastos, la CNMyMyLH consideró que a diferencia de los otros museos, el Mitre debería privilegiar la

\footnotetext{
15 Decreto del Poder Ejecutivo, de fecha 28 de abril de 1938, creando la Comisión Nacional de Museos y de Monumentos y Lugares Históricos. COMISIÓN NACIONAL DE MUSEOS Y DE MONUMENTOS Y LUGARES HISTÓRICOS 1941, p. 232-235. Los otros museos que dependían de la entidad eran el MHN, el Museo y Biblioteca de la Casa del Acuerdo de San Nicolás inaugurado en 1936, el Museo Histórico Sarmiento organizado en 1938 y la Casa de Sarmiento en la provincia de San Juan; al respecto ver AUTOR/A 2012.

${ }_{16}$ Luis tenía 68 años y entre sus múltiples ocupaciones alternaba su puesto en el directorio de La Nación con su primo Jorge. Sobre la renuncia y actuación de Zabala Actas; sesión del 30/5 y 14/6/1938, COMISIÓN NACIONAL DE MUSEOS Y DE MONUMENTOS Y LUGARES HISTÓRICOS 1939, p. 188-190 y 194.
} 
compra y encuadernación de libros para sostener y ampliar su valiosa biblioteca. Aunque hay indicios de que los fondos públicos continuaron siendo escasos, es evidente el interés de Levene y sus colegas por persuadir a los funcionarios de la necesidad de invertir mayor presupuesto.

Pero el cambio más significativo que tuvo el Museo Mitre desde 1938 fue el aumento y diversificación de su público vinculado entre otras cosas a las acciones implementadas por la CNMyMyLH en los museos de Buenos Aires. Ellas se plasmaron en dos iniciativas concretas: la ampliación de los horarios de atención y la institucionalización de "visitas explicadas" para divulgar la "historia patria". La primera medida fue propuesta en 1938 por Enrique Udaondo - vocal de la Comisión Nacional- para que los museos abrieran de martes a domingo como lo hacía el Museo de Luján que dirigía: ello no llegó a implementarse en los inmediato por la escasez de personal pero logró que la biblioteca del Museo Mitre abriera diariamente de 12 a 18 hs y los sábados de 9 a 12 hs - cerrando los lunes- y que el público accediera al Museo lunes y jueves (LEVENE 1939; Actas, sesión del 8/6, del 31/10 y del 7/11 de 1938, COMISIÓN NACIONAL DE MUSEOS Y DE MONUMENTOS Y LUGARES HISTÓRICOS 1939, p. 21, 192, 237-238).

En febrero de 1941el Museo se habilitó también los sábados y en 1942 los domingos por la mañana: la iniciativa no contribuyó a aumentar el número de visitantes pero sí lo hizo la inclusión de un nuevo día para la biblioteca que a partir de ese año funcionó también los jueves (MITRE 1941; 1943; PIQUET 1942; LEVENE 1943).Claramente el público que frecuentaba el instituto estaba 40 mayoritariamente interesado en la investigación pero ello no inhibió que se invitara a visitantes con intereses más heterogéneos para quienes en 1943 se habilitó el Museo los domingos y feriados a la tarde (MITRE, 1944). En diciembre de 1945 el director pidió a la CNMyMyLH ampliar el horario de la biblioteca para que permaneciera abierta doce horas diarias, de 9 a 21 (MITRE 1946). Ello se cumplió a partir de diciembre de 1946 cuando un decreto del Presidente de la Nación Juan Domingo Perón implantó el horario de 7 a 19 hs (MITRE 1948). Para ese entonces Levene había renunciado a la presidencia de la CNMyMyLH.

Respeto a la segunda medida considerada a mediados de 1939 consistía en instituir "visitas explicadas" a los museos con el objeto de promover la participación en actos conmemorativos, mantener vivo el recuerdo de los próceres "patronos" y enseñar a interpretar los objetos que se transformaban en ilustraciones de un relato preestablecido por los historiadores (LEVENE 1940, p. 13-14; Actas, sesión 16/8/1939, COMISIÓN NACIONAL DE MUSEOS Y DE MONUMENTOS Y LUGARES HISTÓRICOS 1940, p. 457). Cabe advertir que por ese entonces la propuesta museográfica iniciada en el Museo Mitre y sustentada en la reconstrucción de ambientes de época estaba en auge aplicada por la CNMyMyLH para ambientar la Sala Capitular del Museo Histórico del Cabildo y la Revolución de Mayo inaugurado en noviembre de 1939 (BLASCO 2014). La primera visita al Museo Mitre se realizó el jueves 7 de septiembre de 1939 ante la presencia de Levene, de los directores de los otros museos, de algunos jefes del Ejército y del grupo de profesores de historia a quienes estaba dirigida la actividad (PIQUET 1940). Los visitantes fueron recibidos por el secretario del Museo y guiados por el Jefe del Archivo 
y el Auxiliar de Biblioteca quienes explicaron el significado de las "reliquias" e invitaron a realizar un minuto de silencio al pasar por la alcoba en donde había fallecido Mitre. Luego visitaron la sede de la $\mathrm{ANH}$, la biblioteca y el archivo y fueron obsequiados con un catálogo del Museo.

Ambas iniciativas incrementaron lentamente el número de concurrentes, propiciaron que los conocimientos se divulgaran en las aulas, que circularan láminas, retratos y postales con "vistas del museo" editadas por la CNMyMyLH (MITRE 1941). Sin embargo el aumento de visitantes estuvo vinculado también a las actividades organizadas por instituciones con sede en el Museo. Entre 1940 y 1945, por ejemplo, el primer y tercer sábado de cada mes la ANH realizó disertaciones y la Institución Mitre dictó conferencias sobre aspectos de la vida del prócer (MITRE 1941; PIQUET 1942). En 1940 se renovaron las muestras del Salón Civil y el Salón Militar del Museo patrocinadas por el Centro Guerreros del Paraguay exponiéndose los cuadros con las escenas de la guerra que el pintor argentino Cándido López había bocetado durante los años en los cuales había estado en los campos de batalla. ${ }^{17}$ Desde 1941 se recuperó la sistematicidad de celebrar el cumpleaños de Mitre cada 26 de junio. ${ }^{18}$ Finalmente, primero la Institución Mitre y desde 1942 también la ANH entregaron premios y diplomas a los mejores estudiantes, a las producciones historiográficas destacadas y a las redacciones sobre temas históricos que consideraban dignas de mención, convocando a estudiantes secundarios, terciarios y universitarios y a sus familias a asistir a las ceremonias y visitar el Museo. ${ }^{19}$

Por otro lado, el Museo también aumentó su caudal de público debido a las medidas adoptadas en el marco de la organización de la Dirección Nacional de Turismo y la redacción del anteproyecto de la Ley Nacional de Turismo en 1941 (BRUNO 2012). El ex director de La Nación Jorge A. Mitre -primo del director del Museo - presidía la flamante Comisión Asesora que también integraba Levene y que durante 1942 se reunía en el Museo (MITRE 1943). A su vez, durante el Congreso Nacional de Turismo realizado en Buenos Aires en agosto de 1942 - del cual Levene era vicepresidente-algunos miembros de la CNMyMyLH presentaron ponencias sobre la conveniencia de señalizar los lugares históricos, editar ilustraciones de monumentos y guías de museos para ser distribuidas entre el público tomando como ejemplo las guías editadas por La Nación sobre el Museo Mitre (Actas, sesión 11/5 y 6/7/1942, COMISIÓN NACIONAL DE MUSEOS Y MONUMENTOS HISTÓRICOS,1943, p. 492, 498, 512. El Congreso Nacional de Turismo y la Comisión Nacional, p. 405-408; MITRE 1943). En un contexto en donde el fomento del turismo era uno de los ejes del gobierno, la casa de la calle

\footnotetext{
${ }_{17}$ El Centro Guerreros del Paraguay era una asociación constituida a fines del siglo XIX por los ex combatientes de la Guerra del Paraguay (1864-1870). Durante la década de 1890 el MHN inauguró una sala con los "trofeos militares" de la contienda y la colección de cuadros de López que congregaba los ex combatientes para realizar actos conmemorativos (CARMAN 2013, p. 156-165).

${ }_{18}$ Al respecto ver los índices de los boletines de la Comisión Nacional editados entre 1942 y 1946.

19 Sobre los premios de la Institución Mitre folio 197 y ss, caja 58, Fondo Enrique Udaondo del Archivo de la AHN. Sobre los premios de la Academia sabemos que por decreto del 29 de septiembre de 1942 el PEN aceptó la donación de \$10.000 efectuada por Levene para instituir un premio anual para alumnos de colegios nacionales, liceos y escuelas normales con promedio sobresaliente en las clases de Historia Argentina y Americana; ver Decreto n. 131763 en: http://www.bnm.me.gov.ar/giga1/normas/13855.pdf.
} 
San Martín fue declarada Monumento Histórico Nacional. Finalmente, desde 1943 la Dirección Nacional de Turismo quedó a cargo de las visitas guiadas a los museos históricos incluyéndolas en los programas de excursiones a la ciudad. ${ }^{20}$ Estas iniciativas contribuyeron a que durante el año 1943 el Museo Mitre alcanzara los 17.780 visitantes anuales (MITRE 1944) lo cual no era un número espectacular pero tampoco nada despreciable (BLASCO 2015).

Para diciembre de 1945, el anciano Luis Mitre continuaba como Director Honorario pero quien lo dirigía en la práctica era su primo Jorge (MITRE 1946), subdirector desde 1944. A mediados de 1946 - a pocos meses de haber asumido la presidencia Juan Domingo Perón- en el marco de la separación de bienes y preparación de testamentos de la familia Mitre, Luis donó el archivo del prócer al Gobierno Nacional (IMBERT 1948, p. 20-21; Museo Mitre y El archivo del General Mitre: informe agregado al expediente n. 1705-1946, COMISIÓN NACIONAL DE MUSEOS Y MONUMENTOS HISTÓRICOS 1948, p. 224-226 y 331-334). Eran más de diez mil piezas entregadas en carpetas clasificadas por Zabala, colocadas en dos cajas de hierro con destino al Museo Mitre. El Ministerio de Justicia e Instrucción Pública aceptó la donación el 11 de septiembre y los miembros de la CNMyMyLH la recibieron el 24.

A partir de ese momento, el edificio, el Museo, la biblioteca y ahora el codiciado archivo privado de Mitre eran propiedad de la nación, solventados y protegidos con fondos públicos. Habían pasado cuarenta años desde la muerte de su propietario, ochenta y seis desde la actuación de Mitre como gobernador de

42 la provincia de Buenos Aires y más de setenta y cinco desde su alejamiento del cargo de Presidente de la Argentina unificada. Era tiempo suficiente para abrir el debate y estimular la producción historiográfica sobre la actuación pública de Mitre. Pero la consagración como prócer de la Argentina moderna promovida desde el Museo terminó de constatarse en 1948 cuando un decreto del Presidente Perón nacionalizó el Ferrocarril Central Argentino bautizándolo Bartolomé Mitre. Justamente ese año - y al menos hasta 1956 - los descendientes del prócer se desvincularon del Museo que habían contribuido a organizar. ${ }^{21}$

\section{Conclusión}

Organizado en el marco de una formación estatal reciente y en un contexto de ausencia de instituciones públicas en donde desarrollar la investigación histórica (BUCHBINDER 1996), el Museo surgió como espacio de conmemoración de la familia Mitre que al donar parte de las colecciones del fallecido al Estado Nacional comprometió e involucró al resto de la dirigencia política en la conformación de la primera institución dedicada a recordar la vida y obra de un hombre devenido "prócer". Se trataba de un uso deliberadamente político del pasado (CATTARUZZA 2007) sustentado en la idea hegemónica de que Mitre había sido el artífice y

\footnotetext{
${ }^{20}$ La primera visita organizada bajo esta estructura se realizó el 8 de junio de 1943 - en medio de la conmoción política por el derrocamiento del gobierno de Ramón Castillo y la jura presidencial del General Pedro P. Ramírez- y tuvo como destino el MHN; Levene (1944 p. 30-34); también Memorias de los Directores del Museos, Comisión Nacional de Museos y Monumentos Históricos (1944, p. 375- 387).

${ }^{21}$ Entre 1948 y 1956 el Museo fue dirigido por Juan Ángel Farini. Luis Mitre falleció en 1950.
} 
constructor del Estado Argentino moderno. Esta idea sumada al funcionamiento de un sistema de socialización basado en círculos privados y por lo tanto a la intervención activa de la familia Mitre, condicionó no solo el carácter público del Museo sino también la producción, interpretación y divulgación de relatos de un pasado de la Argentina unificada que para la década de 1910 era aún demasiado cercano. La propuesta de los descendientes de no donar los documentos inéditos vinculados a la actuación política de Mitre da cuenta de ello, como así también la decisión de los historiadores de incorporar a sus nietos a la JHNA, estableciendo una idea de continuidad entre el constructor del Estado, el productor del gran relato historiográfico de la Nación y la historia como saber disciplinar.

Una vez instalado, el Museocongregó a los estudiosos de la JHNA en torno a los libros y documentos, materia prima para la producción historiográfica. Pero la decisión de la familia Mitre de no alterar la disposición original del mobiliario posibilitó que los eruditos experimentaban también con la posibilidad de ilustrar los aspectos más representativos de la vida y obra del "gran hombre" mediante la exhibición de los objetos que le había pertenecido. El grupo de historiadores que se autodefinían como discípulos de Mitre fueron construyendo la percepción de que la puesta en escena de los objetos era un modo didáctico y novedoso de representar el gran relato de la "historia patria" elaborada por el historiador. Si en la década de 1910 y 1920 la inquietud principal era la colección de libros y documentos para la producción y circulación de conocimiento entre los eruditos, en los años siguientes el interés se trasladó a la extensión cultural en el marco de un programa político de marcado acento nacionalista.

De este modo, el Museo Mitre constituyó el espacio donde los historiadores comenzaron a diseñar una propuesta cultural integral impulsada desde el Estado para fomentar el culto de la historia patria: ese proyecto no solo contemplaba la institucionalización del culto a Mitre y su integración dentro del panteón de próceres sino también la transformación de las exhibiciones museográficas y los museos en dispositivos centrales para divulgar su culto. En este marco, la constitución de la CNMyMyLH y el conjunto de iniciativas desplegadas desde 1938 bajo dirección de Levene podría invitar a interrogarnos acerca de las lógicas de funcionamiento y de los sistemas relacionales de poder en la configuración de un campo cultural (BOURDIEU 1990). Más específicamente, podría estimular a reflexionar sobre la estrecha relación entre la institucionalización del campo historiográfico y la conformación inicial de un campoc on mayor grado de especificidad vinculado a la preservación del patrimonio histórico.

Futuras investigaciones deberán explorar las particularidades del proceso de profesionalización de la museología en la Argentina durante la segunda mitad del siglo XX y las causas que provocaron la desvinculación de los historiadores que, como señalamos, persiste en la actualidad. Pero ello requiere no solo de un corpus de sólidas investigaciones empíricas sobre la vida cultural, el funcionamiento de las instituciones y la conformación de nuevas áreas disciplinares; también de la capacidad para problematizar, como lo ha señalado Eujanian (2003), sobre la historia de la historiografía como área de estudios que centre su mirada en las prácticas desarrolladas también en ámbitos alternativos a los espacios académicos. 


\section{Referencias bibliográficas}

AAVV. En memoria de Don Rómulo Zabala. Buenos Aires: s/e, 1950.

BLASCO, MARÍA ELIDA. Un museo para la colonia. El Museo Histórico y Colonial de Luján, 1918-1930. Rosario: Prohistoria, 2011.

. De objetos a "Patrimonio moral de la nación": prácticas asociadas al funcionamiento de los museos históricos en la Argentina de las décadas de 1920 y 1930 . Nuevos Mundos, 2012. Disponible en: http://nuevomundo. revues.org/64679.

- La intervención de los historiadores en la organización del Museo Histórico del Cabildo y la Revolución de Mayo (Buenos Aires - Argentina1938-1943). Patrimonio e Memória, v. 10, n. 1, p. 4-27, 2014.

- La asistencia de público a los museos históricos de Buenos Aires durante

la década de 19409.Boletín del Instituto de Historia Argentina y Americana "Dr. Emilio Ravignani", 2015 [en prensa].

. El legado mitrista. La arquitectura de consensos para la construcción del prócer Bartolomé Mitre (1906-1938). Prohistoria, Rosario, 2015a [en evaluación].

BISSO, Andrés; KAHAN, Emmanuel. Introducción. En BISSO, Andrés; KAHAN, Emmanuel; SESA, Leandro (ed.). Formas políticas de celebrar y conmemorar el pasado (1930-1943). Buenos Aires: Ceraunia, 2014, p. 7-24.

BOURDIEU, Pierre. Algunas propiedades de los campos. En BOURDIEU, P. Sociología y cultura. México: Consejo Nacional para la Cultura y las Artes/Grijalbo, 1990, p. 135-141.

BRUNO, Perla. Los hoteles de turismo (1930-1955): piezas claves del territorio turístico de la Argentina. Registros, n. 9, p. 54-80, 2012.

BUCHBINDER, Pablo. Vínculos privados, instituciones públicas y reglas profesionales en los orígenes de la historiografía argentina. Boletín del Instituto de Historia Argentina y Americana "Dr. Emilio Ravignani", n. 13,1996 , p. 59-82.

CARMAN, Carolina. Los orígenes del Museo Histórico Nacional. Buenos Aires: Prometeo, 2013

CATTARUZZA, Alejandro. Descifrando pasados: debates y representaciones de la historia nacional". En CATTARUZZA, Alejandro (dir.). Nueva Historia Argentina. Crisis económica, avance del estado e incertidumbre política (1930-1943). Tomo 7. Buenos Aires: Sudamericana, 2001, p. 429-476.

El revisionismo: itinerario de cuatro décadas. En CATTARUZZA, Alejandro; EUJANIAN, Alejandro. Políticas de la historia: Argentina 1860-1960. Buenos Aires: Alianza, 2003, p. 143- 182. 
. Los usos del pasado. La historia y la política argentinas en discusión, 1910-1945. Buenos Aires: Sudamericana, 2007

COMISIÓN NACIONAL DE MUSEOS Y DE MONUMENTOS Y LUGARES HISTÓRICOS.

Boletín de la Comisión Nacional de Museos y de Monumentos y Lugares Históricos, n. 1, Buenos Aires: Imprenta de la Universidad de Buenos Aires, 1939.

Boletín de la Comisión Nacional de Museos y de Monumentos y Lugares Históricos, n. 2. Buenos Aires: Imprenta de la Universidad de Buenos Aires, 1940.

Boletín de la Comisión Nacional de Museos y de Monumentos y Lugares Históricos, n. 3. Buenos Aires: Imprenta de la Universidad de Buenos Aires, 1941.

COMISIÓN NACIONAL DE MUSEOS Y MONUMENTOS HISTÓRICOS. Boletín de la Comisión Nacional de Museos y Monumentos Históricos, n. 4. Buenos Aires: Imprenta de la Universidad de Buenos Aires, 1942.

. Boletín de la Comisión Nacional de Museos y Monumentos

Históricos, n. 5. Buenos Aires: Imprenta de la Universidad de Buenos Aires, 1943.

- Boletín de la Comisión Nacional de Museos y Monumentos Históricos, n. 6. Buenos Aires: Imprenta de la Universidad de Buenos Aires, 1944.

. Boletín de la Comisión Nacional de Museos y Monumentos

Históricos, n. 7. Buenos Aires: Imprenta de la Universidad de Buenos Aires, 1945.

Boletín de la Comisión Nacional de Museos y Monumentos Históricos, n. 8. Buenos Aires: Imprenta de la Universidad de Buenos Aires, 1946.

Boletín de la Comisión Nacional de Museos y Monumentos Históricos, n. 9. Buenos Aires: Imprenta Ferrari Hermanos, 1948.

DEVOTO, Fernando; PAGANO, Nora. Historia de la historiografía argentina. Buenos Aires: Sudamericana, 2009.

DIRECCIÓN GENERAL DE ESTADISTICA Y CENSO. Anuario estadístico 2011. Ciudad de Buenos Aires: Ministerio de Hacienda, Gobierno de la Ciudad de Buenos Aires, 2011.

EUJANIAN, Alejandro. Método, objetividad y estilo en el proceso de institucionalización, 1910-1920. En CATTARUZZA, Alejandro; EUJANIAN, Alejandro. Políticas de la Historia. Argentina 1860-1960. Buenos Aires: Alianza, 2003, p. 69-99.

GIRBAL DE BLACHA, Noemí. Renovación y proyección nacional e internacional de la Junta. Ricardo Levene (1927-1931/1934-19389 y la gestión Ramón 
J. Cárcano- Carlos Correa Luna (1931-1934). En: La Junta de Historia y Numismática Americana y el movimiento historiográfico en la Argentina (1893-1938). Tomo I. Buenos Aires: Academia Nacional de la Historia, 1995, p. 124-167.

IMBERT, Aníbal F. Memoria correspondiente al año 1946, elevada el 31 de marzo de 1947. Boletín de la Comisión Nacional de Museos y Monumentos Históricos, n. 9. Buenos Aires: Imprenta Ferrari Hermanos, 1948, p. 7-29.

LEVENE, Ricardo. Memoria correspondiente al año 1938. Boletín de la Comisión Nacional de Museos y de Monumentos y Lugares Históricos, n. 1. Buenos Aires: Imprenta de la Universidad de Buenos Aires, 1939, p. 15-23 - Memoria correspondiente al año 1939. Boletín de la Comisión Nacional de Museos y de Monumentos y Lugares Históricos, n. 2. Buenos Aires: Imprenta de la Universidad de Buenos Aires, 1940, p. 5-24 . Memoria correspondiente al año 1942. Boletín de la Comisión Nacional de Museos y Monumentos Históricos, n. 5. Buenos Aires: Imprenta de la Universidad de Buenos Aires, 1943, p. 7-45

- Memoria correspondiente al año 1943. Boletín de la Comisión Nacional de Museos y Monumentos Históricos, n. 6. Buenos Aires: Imprenta de la Universidad de Buenos Aires, 1944, p. 7-50

MITRE, Luis. Memoria elevada a Ricardo Levene el 17 de diciembre de 1940.

Boletín de la Comisión Nacional de Museos y de Monumentos y Lugares Históricos, n. 3.1941, p. 399-401.

. Memoria elevada a Ricardo Levene el 7 de diciembre de 1942. Boletín de la Comisión Nacional de Museos y Monumentos Históricos, $n$. 5. Buenos Aires: Imprenta de la Universidad de Buenos Aires, 1943, p. 257-259.

. Memoria elevada a Ricardo Levene el 9 de diciembre de 1943. Boletín de la Comisión Nacional de Museos y Monumentos Históricos, n. 6. Buenos Aires: Imprenta de la Universidad de Buenos Aires, 1944, p. 387-389.

. Memoria elevada a Aníbal F. Imbert el 31 de diciembre de 1946. Boletín de la Comisión Nacional de Museos y Monumentos Históricos, n. 9. Buenos Aires: Imprenta Ferrari Hermanos, 1948, p. 224-226

MITRE, Jorge A. Advertencia. En Archivo del General Mitre. Documentos y correspondencia. Presidencia de la República. Campaña electoral (186768). Intervención nacional a Santa Fe (1868). Tomo I. Buenos Aires: Biblioteca de La Nación, 1911.

. Memoria elevada a Ricardo Levene el 13 de diciembre de 1945. Boletín de la Comisión Nacional de Museos y de Monumentos y Lugares Históricos, n. 8. Buenos Aires: Imprenta de la Universidad de Buenos Aires, 1946, p. 350-352. 
MUSEO MITRE. Archivo Colonial. Tomo I, Buenos Aires: Imprenta Rodríguez Giles, 1914.

Inventario del Museo Mitre. Museo y Oficinas. (Este inventario solamente comprende la sección Museo, así como el mobiliario y útiles de las Oficinas. En cuanto al contenido de la Biblioteca, Monetario, Archivo y Mapoteca consta en los respectivos catálogos). Buenos Aires: Imprenta y Casa Editora Coni, 1937.

Quien es Quien en la Argentina. Biografías contemporáneas. Buenos Aires: Guillermo Fraft, 1955.

RAVINA, Aurora. La fundación, el impulso mitrista y la definición de los rasgos institucionales. Bartolomé Mitre (1901-1906) y Enrique Peña (19061911). En: La Junta de Historia y Numismática Americana y el movimiento historiográfico en la Argentina (1893-1938). Tomo I, Buenos Aires: Academia Nacional de la Historia, 1995, p. 23-59.

. Nuevos proyectos, nuevos miembros, nuevos tiempos. Enrique Peña (1911-1915) y Marcó del Pont- Antonio Dellepiane (1915-1919). En La Junta de Historia y Numismática Americana y el movimiento historiográfico en la Argentina (1893-1938). Tomo I, Buenos Aires: Academia Nacional de la Historia, 1995, p. 61-93.

JUNTA DE HISTORIA Y NUMISMÁTICA AMERICANA. Boletín de la Junta de Historia y Numismática Americana, v. X. Buenos Aires: Talleres Gráficos Rodríguez Giles, 1937.

PIQUET, Julio. Museo Mitre. Primera visita explicada a los profesores de historia.

Boletín de la Comisión Nacional de Museos y Monumentos y Lugares Históricos, n. 2. Buenos Aires: Imprenta de la Universidad de Buenos Aires, 1940, p. 175-177.

. Memoria elevada a Ricardo Levene el 22 de diciembre de 1941. Comisión

Nacional de Museos y Monumentos Históricos, n. 4. Buenos Aires: Imprenta de la Universidad de Buenos Aires, 1942, p. 471-474.

QUATTROCCHI- WOISSON, Diana. Los males de la memoria. Historia y política en la Argentina. Buenos Aires: Emecé, 1995

RODRÍGUEZ, Martha. Cultura y educación bajo el primer peronismo. El derrotero académico institucional de Ricardo Levene. En PAGANO, Nora; RODRÍGUEZ, Martha (comp.). La historiografía rioplatense de la segunda posguerra. Buenos Aires: La Colmena, 2001, p. 39-65.

SUAREZ, Carlos A.; SAAB, Jorge. El Estado, Ricardo Levene y los lugares de memoria. Clío y Asociados, n. 16, 2012, pp. 211-227.

ZIMMERMANN, Eduardo. La prensa y la oposición política en la Argentina de comienzos de siglo: el caso de "La Nación" y el Partido Republicano. Estudios Sociales, n. 15, 1998, p. 45-70. 